\title{
CORRESPONDENCE
}

The NHS is dead: long live the NHS

Sir Alec Merrison, DL, FRS............102

Molar dosage of calcium chloride solutions

D A Chamberlain, FRCP, and others.....102

SI: two years on

Eva Lester, MRCPATH.............. 102

Propranolol absorption in Crohn's

disease and coeliac disease

R L Parsons, MRCP, and others . . . . . . 103

Saving money by self-help

D H Ryde, MRCGP; R Law, MRCGP; S L H

Smith, MRCGP...................

Vitamin $D$ status in different subgroups of British Asians

C $\mathrm{T}$ Dollery, FRCP, and others; $M R$

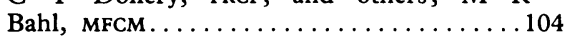

Asthma: Spinhaler usage warning

D C Quantock, MD . . . . . . . . . . . . 104

Metronidazole and anaerobic sepsis Susannah J Eykyn, MRCPATH, and I Phillips, MD; J H B Scarpello, MRCP............ 104

Oestrogens for menopausal flushing

$S$ Campbell, MrCoG, and M I Whitehead,

мB....................... 104
Clonidine and facial flushing in rosacea

W J Cunliffe, MD, and others...........105

D-Penicillamine and fatal obliterative bronchiolitis

W H Lyle, MD . . . . . . . . . . . . . . . . . . 105

Prostatic cancer

L A Price, MRCP, and Bridget T Hill, PHD. . 105

Use of cardiac pacemakers in Britain

H Campbell, FFCM; E T Mathews, FFARCs;

G E Sowton, FRCP............ 106

Quis whatsit?

J S Bradshaw, MB.............. 106

Prescribe British

R B Arnold, PHD . . . . . . . . . . . . . . 107

Chiropody services

G C Jenkins, FCIS

Effect of oral contraceptives on plasma

testosterone concentration

Margaret C K Browning, BSC, and J A R

Anderson, MRCP.................107

Contraceptive dynamism

J A McGarry, FRCOG............. 107

Spontaneous pneumothorax

T Semple, FRCP.............. 107
Retinal vein occlusion

S P B Percival, frCs................ 108

Timing of cervical smears

R Simmons, MRCOG..............108

Integrated approach to asthma

B D Lask, MRCPSYCH . . . . . . . . . . . 108

Management of appendicitis

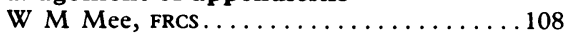

Hip fractures up to date?

G K Morris, MD, and J R A Mitchell, FRCP . 108

Russian roulette

B Haigh, MD . . . . . . . . . . . . . . . 109

Overseas doctors, the BMJ, and the EEC

S S Chatterjee, FRCP............... 109

Recruitment to community medicine

K F R Schiller, DM............... 109

Points from letters Sydney's radio doctor service ( $R$ Tym); Unilateral thoracic hyperhidrosis in bronchial carcinoma (J C Walsh and others); Depression on holiday (M V Silbert); Insulin U40, U80, or U100? (G A Matthews); Competence to practise (J F

Gordon); Chemotherapy for osteosarcoma

(K W Beetham)..................109
Correspondents are urged to write briefly so that readers may be offered as wide a selection of letters as possible. So many are being received that the omission of some is inevitable. Letters should be signed personally by all their authors.

\section{The NHS is dead: long live the NHS}

SIR,-My attention has been drawn to an "open letter" to me in your issue of 4 December ( $p$ 1376) in which Dr Terry Davies declares that in the Earl Grey lecture I gave in Newcastle earlier this year my "message was to beware of the malicious influence of the Civil Service on, not only Ministers of the Crown, but also on nominated advisory bodies, of which you have had considerable experience."

That is, I am afraid, a complete travesty of what I said. I can best illustrate this by quoting merely one paragraph from my lecture, which occurs after a lengthy account I had given of the decision of the Secretary of State for the Environment, in which I had been very much concerned, to impose traffic restrictions on steel box girder bridges on 16 June 1971 . The paragraph runs:

"Then there were his [the Secretary of State's] officials who again had acted correctly and honourably throughout and, with one exception, had acted with good judgment. That exception was of course on the question of whether, in the rather crude knowledge we had, further measures were needed to protect the public safety. It was a matter of judgment and I believe they got it wrong.'

How that can be translated into "malicious influence" I cannot for the life of me imagine. We all of us make mistakes-even Dr Davies, I am afraid, since his table of mortality of myocardial infarction patients in various hospitals is wholly without meaning until one has the numbers (not percentages) of patients treated so that one can at least judge the statistical reliability of his table. Even with that knowledge the cases would have to be subjected to a good deal of clinical analysis before one could draw the conclusions which Dr Davies is after.

All this is rather a pity since I have found this series of open letters which you have been running most helpful and illuminatingas I am sure my fellow Commissioners have, too.

\section{The University,}

Alec Merrison

Bristol

Molar dosage of calcium chloride solutions

SIR,-Mrs S M Roden and Mr G A Mander (20 November, p 1255) illustrate how confusing calcium chloride preparations are for clinicians and pharmacists but overlook the point of our letter (30 October, p 1068). There are now preparations in different strengths and different degrees of hydration; moreover, different manufacturers use different conventions on their labels. They quote the Evans label, while our objections are to that of McCarthy Laboratories, on one of which is printed only: " $2.5 \mathrm{mmol}$ of calcium ions in $5 \mathrm{ml}$." There is no mention of the metric or percentage equivalent and the manufacturers assume that the prescriber has used the SI derived unit on the prescription sheet or drug record. The DHSS circular on the introduction of SI units into the NHS (HSC (IS) 140) gives no authority for this, stating that doses are to be in metric (SI) units (appendix I, p 7); the use of molar (SI) units clearly contravenes this instruction. When we asked who initiated the change we were informed that it was instigated by several area pharmacists. In Brighton as elsewhere we have used SI units for 20 years; our objections, as clinicians, are primarily with the derived units and now with the unauthorised molar form for prescribing, dispensing, and dosage. This is the result of absurd and uncontrolled adumbrations in the adoption of a derived unit of the Système International.

We suggest that the concentration of calcium chloride solutions should be expressed in weight/volume terms in respect of the anhydrous compound. This would have the virtues of simplicity, uniformity, and safety. It would also conform with the current SI instructions. Unfortunately we practise in days in which the simple and rational seem to be unacceptable.

D A Chamberlain A N G Clark JOANNA SHELDON

Brighton Health District,

Brighton, Sussex

\section{SI: two years on}

SIR,-In spite of all the kicking and screaming a year or two ago SI units have been introduced into over $90 \%$ of chemical pathology laboratories in the United Kingdom and the topic is, if not a dead duck, certainly a moribund one here. Before we bury it, though, we should remember that the "I" in SI stands for 